higher injury severity, factors associated with increased odds of disability were not common to both groups. Where possible, studies which include both hospitalised, and non-hospitalised, are likely to increase our understanding of disability outcomes.

\section{1 PRE-INJURY AND INJURY-RELATED PREDICTORS OF DISABILITY 3 AND 12 MONTHS AFTER INJURY: HOSPITALISED AND NON-HOSPITALISED}

doi:10.1136/injuryprev-2012-040580b.11

${ }^{1} \mathrm{~S}$ Derrett*, ${ }^{1} \mathrm{~A}$ Samaranayaka, ${ }^{1} \mathrm{~S}$ Wilson, ${ }^{1} \mathrm{JD}$ Langley, ${ }^{2} \mathrm{~S}$ Ameratunga, ${ }^{3} \mathrm{ID}$ Cameron, ${ }^{1} \mathrm{R}$ Lilley, ${ }^{4} \mathrm{E}$ Wyeth, ${ }^{2} \mathrm{G}$ Davie. ${ }^{1}$ Injury Prevention Research Unit, Department of Preventive and Social Medicine, Dunedin School of Medicine, University of Otago, New Zealand; ${ }^{2}$ School of Population Health, Faculty of Medical and Health Sciences, University of Auckland, New Zealand; ${ }^{3}$ Rehabilitation Studies Unit, Sydney Medical School, University of Sydney, Australia; ${ }^{4}$ Te Roopū Rangahau Hauora Māori a Ngāi Tahu (Ngāi Tahu Māori Health Research Unit), Department of Preventive and Social Medicine, Dunedin School of Medicine, University of Otago, New Zealand

Background Most studies of injury outcome are restricted to hospitalised people. Little is known about outcomes for those not hospitalised, and few studies have used validated measures of disability.

Aims We identify factors associated with disability among hospitalised and non-hospitalised people, 3- and 12-months after injury.

Methods The Prospective Outcomes of Injury Study recruited participants $(n=2856)$ via New Zealand's no-fault injury compensation insurer (ACC) database. A wide range of pre-injury demographic, health and injury-related characteristics were collected at interview. Injury severity scores (NISS) and 12 injury categories were derived from ICD-10 codes. The World Health Organisation's WHODAS 12-item instrument was used to assess disability. Multivariable analyses examine relationships between explanatory variables and disability at both time-points.

Results Disability was prevalent among hospitalised and nonhospitalised participants, 3-months after injury (54\% and 39\% respectively). In both groups pre-injury disability, obesity and more severe injuries were associated with increased odds of post-injury disability. A range of other pre-injury demographic, health and injury-related factors were associated with disability, but only in one group for example, female $(\mathrm{OR}=1.78), \geq 2$ chronic conditions $(\mathrm{OR}=1.92)$ or leg fracture $(\mathrm{OR}=3.50)$ among hospitalised; age $35-54$ years $(\mathrm{OR}=1.40)$, trouble accessing healthcare $(\mathrm{OR}=1.92)$, spine sprains/strains $(\mathrm{OR}=2.21)$ and assault $(\mathrm{OR}=3.04)$ among non-hospitalised.

Significance Post-injury disability is prevalent, regardless of being hospitalised or not. Apart from pre-injury disability, obesity and 